\title{
Studi Etnofarmakologi Obat Tradisional Tekanan Darah Tinggi Di Desa Onepute Kecamatan Petasia Barat Kabupaten Morowali Utara
}

\author{
Hamra Sakaria ${ }^{{ }^{*}}$, Amelia Rumi $^{1}$, Andi Atirah Masyita $^{1}$ \\ ${ }^{1}$ Jurusan Farmasi, Universitas Tadulako, Palu, Indonesia
}

*Email: hamrasakaria@gmail.com

\begin{abstract}
High blood pressure is one of the main risk factors for cardiovascular disease which causes 20-50\% of all deaths. The people of Onepute, West Petasia District, North Morowali Regency have a very high percentage of high blood pressure with a percentage of $65 \%$. One of the risk factors for high blood pressure is consuming foods high in fat and salt, medicinal plants are plants or parts of plants commonly used by Indonesian people as an alternative to treat various diseases. The purpose of this study was to determine the types and parts of plants used, processing, how to use, the rules of use or the dosage of treatment, as well as the compatibility between empirical knowledge of the Onepute community, West Petasia District, North Morowali Regency with ethnopharmochological studies that had been previously researched. The research method used was purposive sampling method, namely the technique of taking members of the sample from the population with certain considerations. The research was conducted by means of semi-structured interviews with open questions to 6 sandro people of the Onepute community, West Petasia District, North Morowali Regency and the form of data presentation in a qualitative way. The results showed that there were 6 types of plants, and what is widely used by the community is leaves with a percentage of $66.67 \%$. Plant parts used include leaves, fruit and rhizomes. The processing method is boiled, squeezed, brewed and direct consumption. Compounds that play a role in lowering high blood pressure are monotetrahydrofuran acetogenin compounds, such as anomuricin A and B, gigantetrosin A, annonasin-10-one, muricatosin A and B, annonacin, and goniothalamicin, postasium, potassium, gingerol, shogaol, sodium, flavonoids, tannins, triterpenoids, saponins, polyphenols.
\end{abstract}

Keywords: Ethnopharmacology, High Blood Pressure Disease, Onepute Society.

\begin{abstract}
ABSTRAK
Penyakit tekanan darah tinggi yaitu salah satu faktor risiko utama yang menyebabkan penyakit kardiovaskular yang menyebabkan 20-50\% dari seluruh kematian. Masyarakat Onepute Kecamatan Petasia Barat Kabupaten Morowali Utara memiliki persentase yang sangat tinggi terhadap penyakit tekanan darah tinggi dengan persentase $65 \%$. Salah satu faktor risiko penyakit tekanan darah tinggi yaitu dengan mengkonsumsi makanan tinggi lemak dan garam, tumbuhan obat merupakan tumbuhan atau bagian tanaman yang biasa digunakan oleh masyarakat Indonesia sebagai salah satu alternatif guna mengobati berbagai penyakit. Tujuan penelitian ini untuk mengetahui jenis dan bagian-bagian tumbuhan yang digunakan, pengolahan, cara penggunaan, aturan pakai atau takaran pengobatan, serta kesesuaian antara pengetahuan masyarakat Onepute Kecamatan Petasia Barat Kabupaten Morowali Utara secara empiris dengan kajian etnofarmokologi yang sudah diteliti sebelumnya. Metode penelitian yang digunakan dengan teknik metode purposive sampling yaitu teknik pengambilan anggota sampel dari populasi dilakukan dengan pertimbangan tertentu. Penelitian dilakukan dengan cara wawancara semi terstruktur dengan pertanyaan terbuka pada 6 orang sandro masyarakat Onepute Kecamatan Petasia Barat Kabupaten Morowali Utara dan bentuk penyajian data dengan cara kualitatif. Hasil penelitian menunjukkan terdapat 6 jenis tumbuhan, dan yang banyak digunakan oleh masyarakat adalah daun dengan persentase 66,67\%. Bagian tumbuhan yang digunakan antara lain daun, buah, dan rimpang. Cara pengolahannya yaitu direbus, diperas, diseduh dan konsumsi langsung. Senyawa yang berperan dalam penurunan darah tinggi yaitu senyawa monotetrahidrofuran asetogenin, seperti anomurisin A dan B, gigantetrosin A, annonasin-10-one, murikatosin A dan B, annonasin, dan goniotalamisin, postasium, kalium, gingerol, shogaol, natrium, flavonoid, tannin, triterpenoid, saponin, polifenol.
\end{abstract}

Kata kunci: Etnofarmakologi, Penyakit Tekanan Darah Tinggi, Masyarakat Onepute. 


\section{Pendahuluan}

Tekanan darah tinggi didefinisikan sebagai tekanan darah sistolik (TDS) rata-rata $\geq 140 \mathrm{mmHg}$ atau tekanan darah diastolik rata-rata (TDD) $\geq 90 \mathrm{mmHg}$, tekanan darah tinggi yang tidak terkontrol didefinisikan sebagai rata-rata TDS $\geq 140 \mathrm{mmHg}$ atau rata-rata TDD $\geq 90 \mathrm{mmHg}$ [2]. dan menurut[7] Tekanan darah tinggi adalah nyeri kepala berdenyut disertai kaku kuduk atau kencang pada leher/bahu. Penyakit tekanan darah tinggi telah menempati kasus nomor 1 yang paling banyak dilaporkan dengan hasil data pemantauan status kesehatan. Berdasarkan data dari Puskesmas Anutoluwu Kecamatan Petasia Barat pada tahun 2019-2020 di desa Onepute jumlah pasien darah tinggi sebesar $65 \%$.

Desa Onepute Kecamatan Petasia Barat Kabupaten Morowali Utara adalah desa yang dimana nama desa Onepute diambil dari bahasa Mori Lolongoio yang artinya "lurus" desa Onepute merupakan suatu desa yang berada di Kabupaten Morowali Utara yang menjadi salah satu desa pedalaman. Hal inilah sesuai dengan tempat tinggal masyarakat yang jauh dari perkotaan, kondisi seperti ini yang membuat mereka masih mengandalkan alam untuk kehidupannya, baik sebagai bahan pangan, bahan industri, serta ramuan obat [5].

Menurut hasil pengamatan terhadap kebiasaan masyarakat Onepute menunjukkan pola hidup yang tidak sehat seperti mengonsumsi makanan yang tinggi lemak dan garam. Banyaknya faktor risiko atau kecenderungan seseorang menderita penyakit tekanan darah tinggi diantaranya seseorang mempunyai ciri-ciri individu seperti umur, jenis kelamin, dan suku, faktor genetik serta lingkungan yang meliputi obesitas, stres, konsumsi alkohol, merokok, dan sebagainya [6].

Salah satu tanaman yang dipercayai oleh masyarakat Onepute dalam mengobati penyakit tekanan darah tinggi yaitu daun sirsak (Annona muricata. L) bagian tanaman yang digunakan untuk pengobatan penyakit tekanan darah tinggi yaitu daun, yang dimana tanaman sirsak yaitu jenis pohon pinus yang mempunyai daun berbentuk bulat Panjang dengan ujung lancip pendek bertekstrur kasar. Nama ilmiah daun sirsak yaitu (Annona Muricata. L) daun sirsak mempunyai kandungan senyawa yang dapat menurunkan tekanan darah tinggi senyawa tersebut adalah monotetrahidrofuran asetogenin, seperti anomurisin A dan B, gigantetrosin A, annonasin10-one, murikatosin $\mathrm{A}$ dan $\mathrm{B}$, annonasin, dan goniotalamisin dan ion kalium. Khasiat senyawa ini untuk pengobatan berbagai penyakit. Kandungan daun sirsak yang lain yaitu kalsium, fosfor, karbohidrat, vitamin A, vitamin B, vitamin $\mathrm{C}$, tanin, fitosterol, kalsium oksalat, dan alkaloid murisine. Daun sirsak memiliki antioksidan yang dapat menangkal radikal bebas, sama halnya dengan bahan alami lainnya, antioksidan ini dapat melenturkan dan melebarkan pembuluh darah serta menurunkan tekanan darah tinggi.[8]

Berdasarkan informasi diatas, telah menjadi informasi dasar yang harus dikaji secara etnofarmakologi untuk penelusuran obat tradisional khusunya penyakit tekanan darah tinggi, sehingga peneliti tertarik untuk melakukan penelitian ini dan mengambil judul "Studi Etnofarmakologi Obat Tradisional Tekanan Darah Tinggi Di Desa Onepute Kecamatan Petasia Barat Kabupaten Morowali Utara"

\section{Metode Penelitian}

Jenis penelitian ini adalah deskriptif yang menggunakan metode kualitatif. Dilakukan dengan cara observasi lapangan dan wawancara menggunakan kuesioner dari[7] untuk mengetahui penggunaan tumbuhan yang diketahui penggunannya oleh masyarakat Onepute Kecamatan Petasia Barat Kabupaten Morowali Utara sebagai obat tekanan darah tinggi. Penelitian ini dilaksanakan dari bulan SeptemberNovember 2020 dilakukan di desa Onepute Kecamatan Petasia Barat Kabupaten Morowali Utara. Alat dan bahan yang digunakan dalam penelitian ini yaitu: alat tulis, gunting, alkohol, kapas, solasi, kantong plastik, koran / kertas bekas, kamera dan alat perekam.

\section{Hasil}

Berdasarkan penelitian obat tradisional yang telah dilakukan di desa Onepute Kecamatan Petasia Barat Kabupaten Morowali Utara didapatkan 6 jenis tumbuhan yang digunakan sebagai obat tekanan darah tinggi oleh masyarakat Onepute. Hasil identifikasi tumbuhan yang dilakukan di Laboratorium Biodeversity Jurusan Biologi Fakultas Matematika dan Ilmu Pengetahuan Alam Universitas Tadulako didapatkan 6 Family tumbuhan dari 6 jenis tumbuhan yang digunakan sebagai obat darah tinggi oleh masyarakat Onepute Kecamatan Petasia Barat Kabupaten Morowali Utara. Tumbuhan dan bagian tanaman yang digunakan sebagai obat darah tinggi oleh masyarakat Onepute Kecamatan Petasia Barat Kabupaten Morowali Utara. Persentase organ tumbuhan yang digunakan untuk obat tekanan darah tinggi oleh masyarakat Onepute Kecamatan Petasia Barat Kabupaten Morowali Utara. 
Volume 6 (1) 2021 p22-27

Tabel 1. Karakteristik Sandro menurut usia, alamat, pendidikan dan pekerjaan

\begin{tabular}{cclll}
\hline No & Nama & Usia & Pendidikan & Pekerjaan \\
\hline 1. & MA & 43 & SMA & Petani \\
2. & Ns & 54 & SD & Ibu Rumah Tangga \\
3. & In & 49 & SD & Ibu Rumah Tangga \\
4. & Ec & 62 & SD & Petani \\
5. & YS & 52 & SMA & Petani \\
6. & Nr & 47 & SD & Petani \\
\hline
\end{tabular}

Tabel 2. Karakteristik Pasien menurut usia, alamat, pendidikan dan pekerjaan

\begin{tabular}{ccccc}
\hline No & Nama & Usia & Pendidikan & Pekerjaan \\
\hline 1. & RS & 35 & SMP & Ibu Rumah Tangga \\
2. & NA & 29 & SMA & Ibu Rumah Tangga \\
3. & Hd & 75 & SD & Petani \\
4. & Nb & 44 & SD & Petani \\
5. & Rs & 22 & SMK & Belum Ada \\
6. & LS & 65 & SMP & Petani \\
\hline
\end{tabular}

Tabel 3. Tumbuhan dan bagian tumbuhan yang digunakan sebagai obat tekanan darah tinggi oleh masyarakat Onepute Kecamatan Petasia Barat Kabupaten Morowali Utara

\begin{tabular}{llll}
\hline No & Nama Tumbuhan & Spesies & Bagian yang digunakan \\
\hline 1. & Belimbing wuluh & Averrhoa bilimbi $\mathrm{L}$. & Buah \\
2. & Sirsak & Annona muricata L. & Daun \\
3. & Kelor & Moringa oleifera Lam. & Daun \\
4. & Jahe merah & Zingiber officinalle Roscoe. & Rimpang \\
5. & Jarak/balacai & Jatropha curcas L. & Daun \\
6. & Kersen/gersen & Muntingia calabura L. & Daun \\
\hline
\end{tabular}

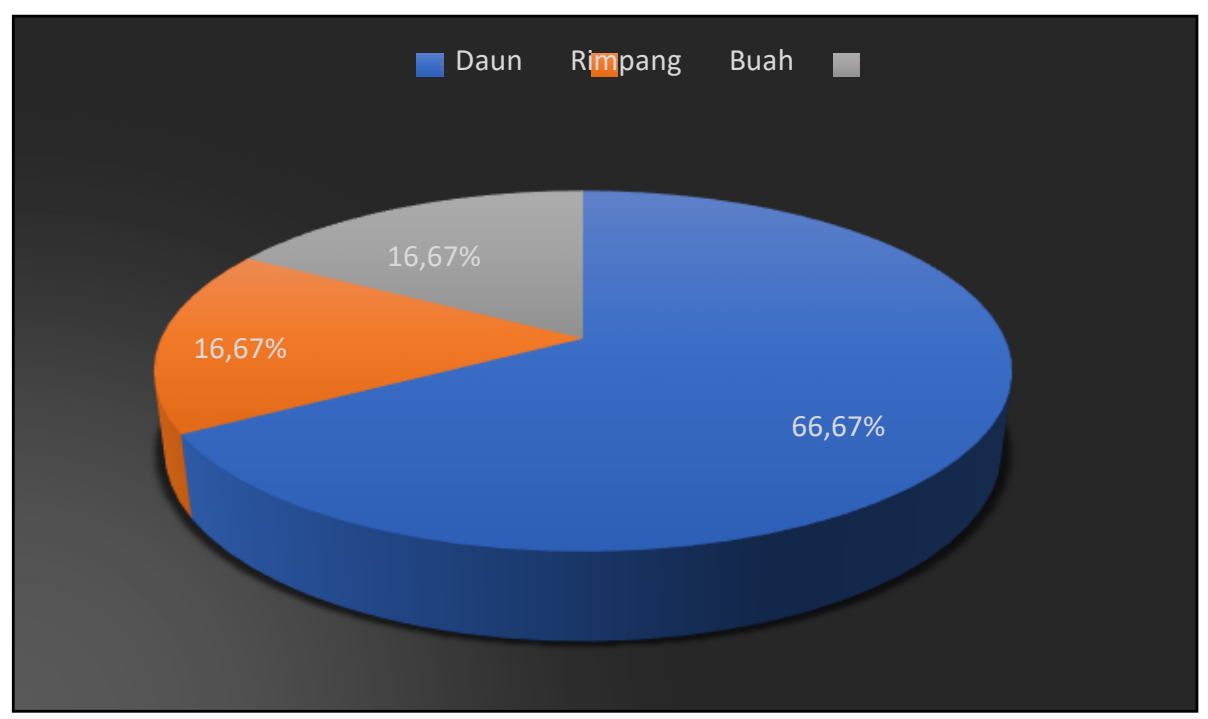

Gambar 1. Persentase Organ Tumbuhan 
Volume 6 (1) 2021 p22-27

Tabel 4. Tumbuhan obat yang memiliki efek farmakologi terhadap tekanan darah tinggi

\begin{tabular}{|c|c|c|c|}
\hline No & $\begin{array}{c}\text { Nama } \\
\text { tumbuhan }\end{array}$ & Kandungan Senyawa & Efek Farmakologi \\
\hline 1. & Daun Sirsak & $\begin{array}{l}\text { monotetrahidrofuran } \\
\text { asetogenin, seperti anomurisin } \\
\text { A dan } \mathrm{B} \text {, gigantetrosin } \mathrm{A}, \\
\text { annonasin } 10 \text {-one, murikatosin } \\
\mathrm{A} \text { dan B, annonasin, dan } \\
\text { goniotalamisin dan ion kalium }\end{array}$ & $\begin{array}{l}\text { Daun sirsak mempunyai antioksidan yang dapat menangkal } \\
\text { radikal bebas, sama halnya dengan bahan alami lainnya, } \\
\text { antioksidan ini dapat melenturkan dan melebarkan } \\
\text { pembuluh darah serta menurunkan tekanan darah.[8] }\end{array}$ \\
\hline 2. & Daun kelor & postasium dan kalium & $\begin{array}{l}\text { Daun kelor mempunyai kandungan postasium dan kalium } \\
\text { yang keduanya sangat baik digunakan untuk kesehatan } \\
\text { tekanan darah seseorang, kalium memelihara tekanan darah } \\
\text { dalam kondisi normal, dan potasium berfungsi untuk } \\
\text { menurunkan tekanan darah. Daun kelor memiliki kaya akan } \\
\text { postasium sehingga kadar sodium dalam darah dapat } \\
\text { dikendalikan yang pada penurunan tekanan darah tinggi.[10] }\end{array}$ \\
\hline 3. & Daun kersen & $\begin{array}{l}\text { flavonoid, tannin, } \\
\text { triterpenoid, saponin, dan } \\
\text { polifenol. Flavonoid }\end{array}$ & $\begin{array}{l}\text { Daun kersen mempunyai kandungan senyawa flavonoid, } \\
\text { tannin, triterpenoid, saponin, dan polifenol. Flavonoid yang } \\
\text { terdapat dalam daun kersen yang berfungsi sebagai obat } \\
\text { tekanan darah tinggi.[3] }\end{array}$ \\
\hline 4. & Jahe merah & Gingerol dan shogaol & $\begin{array}{l}\text { Jahe merah mempunyai kandungan senyawa gingerol dan } \\
\text { shogaol yang dimana pada konsentrasi rendah senyawa } \\
\text { tersebut dapat menurunkan tekanan darah tinggi. Salah satu } \\
\text { manfaat jahe merah yaitu menurunkan tekanan darah tinggi. } \\
\text { Hal inilah yang membuat jahe merah dapat merangsang } \\
\text { pelepasan hormon adrenalin dan memperlebar pembuluh } \\
\text { darah, akibatnya darah mengalir lebih cepat } \\
\text { serta meringankan kerja jantung memompa darah.[4] }\end{array}$ \\
\hline 5. & $\begin{array}{l}\text { Belimbing } \\
\text { wuluh }\end{array}$ & Kalium dan natrium & $\begin{array}{l}\text { Pada dasarnya buah belimbing mempunyai kandungan } \\
\text { kadar kalium yang tinggi serta natrium yang rendah sebagai } \\
\text { obat tekanan darah tinggi yang di mana kandungan kalium } \\
\text { (potasium) dalam } 1 \text { buah belimbing ( } 127 \text { gram) yaitu } \\
\text { sebesar } 207 \mathrm{mg} \text {. Hal ini menunjukkan bahwa kalium dalam } \\
\text { buah belimbing mempunyai jumlah yang paling banyak dari } \\
\text { jumlah mineral yang ada dalam kandungan } 1 \\
\text { buah belimbing.[1] }\end{array}$ \\
\hline
\end{tabular}

Dari hasil studi literatur yang telah dilakukan, didapatkan Penjelasan tentang tumbuhan obat yang memiliki efek farmakologi terhadap tekanan darah tinggi dan beberapa tanaman yang memiliki aktivitas lainnya selain penggunaannya sebagai obat tekanan darah tinggi. Penjelasan tersebut dapat dilihat pada tabel 4 .

\section{Pembahasan}

Desa Onepute merupakan suatu desa yang berada di Kecamatan Petasia Barat Kabupaten Morowali Utara dengan luas 5000 virkan yang terdiri dari 5 dusun. Menurut sejarahnya desa Onepute telah ada sejak tanggal 1 Mei 1959, dengan cikal bakal berdirinya adalah Mangkungku Damantora bersama tokoh-tokoh masyarakat pada masa itu. Desa Onepute sebelum bergabung merupakan bagian dari desa Sampalowo
Kecamatan Petasia Barat. Nama desa Onepute diambil dari Bahasa Mori Lolongoio yang artinya "lurus" oleh karna itu disebelah utara desa Onepute dibangun sebuah pintu gerbang masuk desa Onepute yang sekaligus memisahkan desa Onepute dan desa Sampalowo desa tersebut dibatasi oleh sungai yang dimana dinamakan kali Laa desa Onepute memiliki jumlah penduduk yaitu dimana jumlah kepala keluarga 225 dan 785 jiwa terdiri dari 5 dusun.

Berdasarkan hasil observasi di Puskesmas Anutoluwu desa Onepute Kecamatan Petasia Barat Kabupaten Morowali Utara pada tahun 2019-2020 memiliki persentase yang sangat tinggi terhadap penyakit darah tinggi yaitu dimana berkisar sekitar $65 \%$. Penelitian ini dilakukan di desa Onepute Kecamatan Petasia Barat Kabupaten Morowali Utara pada 5 dusun dan didapatkan 6 orang Sandro dan 6 pasien yang dimana dari 6 pasien tersebut mewakili tiap Sandro, ke enam Sandro tersebut 
bernama yaitu ML, YS, In, Ns, Ec, Nr. Dan ke enam pasien tersebut bernama yaitu LS, Rs, NA, Nb, Hd, Rs. Peneliti memilih pasien dari umur yang mudah sampai yang lanjut usia.

Berdasarkan penelitian yang dilakukan di desa Onepute Kecamatan Petasia Barat Kabupaten Morowali Utara didapatkan 6 jenis tumbuhan sebagai obat tekanan darah tinggi tumbuhan tersebut yaitu belimbing wuluh (Averrhoa bilimbi L.), daun sirsak (Annona muricata L.), daun kelor (Moringa oleifera Lam.), Jahe merah (Zingiber officinale Roscoe.), daun jarak pagar/balacai (Jatropha curcas L.), daun kersen/gersen (Muntingia calabura L.) serta bagian tanaman yang digunakan yaitu daun, buah, dan rimpang diolah secara tradisional. Pengolahan tumbuhan sehingga menjadi ramuan obat tradisional menurut Sandro sebagian besar masyarakat Onepute menggunakan cara tradisional seperti diparut, direbus, dan diseduh menggunakan air panas. Dari cara tersebut yang paling banyak digunakan oleh masyarakat yaitu dengan cara direbus. Mereka memberikan alasan bahwa penggunaan dengan cara direbus adalah cara yang paling efektif. dalam membuat ramuan tumbuhan obat. Dengan cara pengolahan ini pula diyakini sangat mudah dan hemat karena bisa direbus hingga berulang. Cara penggunaan dan takaran yang dianjurkan oleh sandro desa Onepute yaitu dengan cara diminum dan dengan takaran mulai dari $1 \times 1$ gelas, $2 \times 1$ gelas hingga $3 \times 1$ gelas. Cara pengolahan tumbuhan yaitu daun kelor dicuci lalu direbus daun kelor menggunakan air bersih sebanyak 7 gelas air menjadi 3 gelas, belimbing wuluh dicuci belimbing wuluh lalu dipotong-potong direbus 3 gelas air menjadi 1 gelas setelah dingin lalu disaring, jahe merah jahe dibersihkan lalu diparut, ditambahkan air hangat lalu disaring sebanyak setengah gelas, daun jarak pagar diambil beberapa lembar lalu disiram/diseduh menggunakan air diambil beberapa lembar biasanya diambil dalam hitungan ganjil lalu direbus menjadi 1 gelas, daun kersen diambil beberapa lembar daun kersen lalu dicuci setelah itu direbus 3 gelas menjadi 1 gelas

Hasil persentase bagian tumbuhan yang paling besar digunakan sebagai obat tekanan darah tinggi oleh masyarakat Onepute Kecamatan Petasia Barat Kabupaten Morowali Utara yaitu pada bagian daun sebanyak $66,67 \%$, dibandingkan dengan bagian lainnya seperti buah, dan rimpang hanya sebanyak 16,67\%. Mereka menyebutkan bahwa bagian tanaman daun yaitu bagian tanaman yang paling mudah diambil dan ditemukan oleh masyarakat kapan saja pada saat diperlukan, berbeda pada bagian tanaman obat yang lainnya yang biasa tergantung dari musim dan umur tumbuhan misalnya pada bagian buah dan rimpang.

Wawancara yang dilakukan oleh pasien atau penderita penyakit tekanan darah tinggi di desa Onepute Kecamatan
Petasia Barat Kabupaten Morowali Utara, gejala awal yang biasa dirasakan oleh penderita penyakit tekanan darah tinggi sebelum diberikan ramuan obat tekanan darah tinggi yaitu pusing disertai rasa tegang dibagian leher, lemas, detak jantung tidak beraturan, kelelahan, kehilangan keseimbangan, dan penglihatan mulai kabur. Setelah penderita melakukan pengobatan pada dukun dan diberikan ramuan obat tekanan darah tinggi yang telah diresepkan, penderita dapat menunjukkan perubahan kondisi tubuh yang lebih baik dari sebelumnya seperti tidak lagi pusing hingga rasa tegang dibagian leher, tidak lagi merasa lemas dan kelelahan serta detak jantung dan penglihatan normal. Hal ini menunjukkan bahwa pasien atau penderita yang mengkonsumsi ramuan tumbuhan obat yang diberikan oleh Sandro terbukti dapat menyembuhkan penyakit tekanan darah tinggi menurut informasi dari sandro yang menanyakan kembali kepada pasien atau penderita penyakit tekanan darah tinggi yang telah diobati.

Kesembuhan yang dirasakan oleh pasien setelah mengkonsumsi ramuan tumbuhan obat akibat dari adanya senyawa seperti senyawa monotetrahidrofuran asetogenin, seperti anomurisin A dan B, gigantetrosin A, annonasin10one, murikatosin A dan B, annonasin, dan goniotalamisin dan ion kalium yang terdapat pada daun sirsak, postasium dan kalium pada daun kelor, flavonoid, tannin, triterpenoid, saponin dan polifenol pada daun kersen, gingerol dan shogaol pada jahe merah, kalium dan natrium pada buah belimbing. Sedangkan pada daun jarak pagar/balacai belum ditemukan kandungan senyawa terkait efek farmakologi terhadap penyakit hipertensi. Daun jarak pagar/balacai hanya digunakan sebagai pelengkap saja sehingga perlu diteliti lebih lanjut [9].

\section{Kesimpulan}

Berdasarkan penjelasan diatas peneliti dapat menyimpulkan bahwa tumbuhan yang dapat digunakan untuk mengobati tekanan darah tinggi di desa Onepute Kecamatan Petasia Barat Kabupaten Morowali Utara yaitu daun sirsak, daun kelor, daun kersen, daun jarak pagar, belimbing wuluh, dan jahe merah. Serta bagian tumbuhan yang digunakan yaitu daun, buah, dan rimpang. Cara pengolahan dan cara penggunaan pada obat tradisional yaitu dengan cara direbus, diseduh, dan diparut, cara penggunaan yaitu diminum. Senyawa yang berperan dalam penurunan tekanan darah tinggi yaitu senyawa monotetrahidrofuran asetogenin, seperti anomurisin A dan B, gigantetrosin A, annonasin-10-one, murikatosin A dan B, annonasin, dan goniotalamisin, postasium, kalium, gingerol, shogaol, natrium, flavonoid, tannin, triterpenoid, saponin, polifenol. 


\section{Daftar Pustaka}

[1] Bangun, A. V., \& Ahmad, L. N. Pengaruh Terapi Jus Belimbing Manis (Averhoa Carambola Linn) Terhadap Tekanan Darah Lansia Dengan Hipertensi. Jurnal Kesehatan Caring andEnthusiasm, 2016; 4(1).

[2] Centers for Disease Control and Prevention. Vital Signs: Awareness and Treatment of Uncontrolled Hypertension Among adults-United States, 2003-2010. MMWR Morb Mortal, 61, 703-709.

[3] Karsa, S., Asrina, R., Farmasi, A., Karsa, S., Studi, P., Sandi, D. F., \& Makassar, K. Jurnal Farmasi Sandi Karsa ( JFS ). 2012;VI(1), 99-104.

[4] Khare, C. P. Zingiber officinale Rosc. Indian MedicinalPlants,https://doi.org. 2007;007, 1-1.

[5] Lamole, (1959). Sejarah Desa Onepute; Desa onepute kecamatan petasia barat kabupaten morowali utara.

[6] Paat, I. G. ., Ratag, B. T., \& Kepel, B. J. (2014) Hubungan antara Konsumsi Alkohol dan Status Merokok dengan Kejadian Hipertensi pada Laki-Laki Usia 40-65 Tahun di Desa Motoling Kabupaten Minahasa Selatan. Fakultas Kesehatan Masyarakat Universitas Sam Ratulangi Manado.

[7] Ristoja. Laporan Nasional Riset Khusus Ekspolarasi Pengetahuan Lokal Etnomedisin dan Tumbuhan Obat Berbasis Komintas di Indonesia (RISTOJSA) tahun 2015. Balai Besar Penelitian dan Pengembangan Tanaman Obat, 2015;69.

[8] Ristyaning, P., Sangging, A., Rista, M., Sari, N., Klinik, B. P., Kedokteran, F., \& Lampung, U. (2017). Efektivitas Teh Daun Sirsak (Annona muricata Linn) terhadap Hipertensi. Majority, 6(2), 49- 54.

[9] Udarno, B., Budi, M. Pemanfaatan tanaman untuk pengobatan hipertensi diwilayah suaka sangdepaha (gunung salak, gebe, pengrungo dan halumin). Biocelebes, 2013;19(1)-7.

[10] Yanti, E. (2019). pengaruh pemberian rebusan daun kelor (moringa olifiera) terhadap tekanan darah pada penderita hipertensi. Jik: Jurnal Ilmu Kesehatan, 3(1), 24-29. https://doi.org/10.33757/jik.v3i1.164 